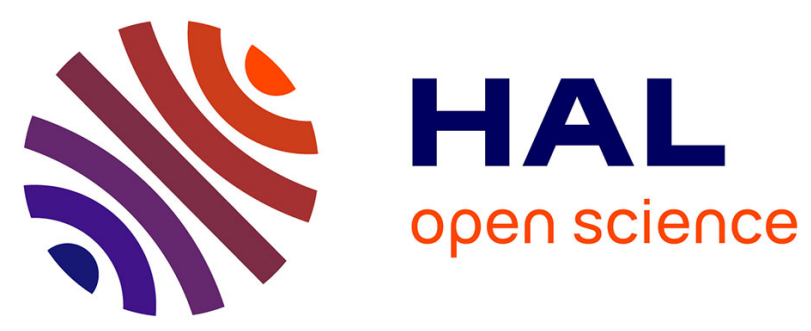

\title{
INFLUENCE OF GENDER ON PACING ADOPTED BY ELITE TRIATHLETES DURING A COMPETITION
}

Yann Le Meur, Christophe Hausswirth, Sylvain Dorel, Frank Bignet, Jeanick Brisswalter, Thierry Bernard

\section{To cite this version:}

Yann Le Meur, Christophe Hausswirth, Sylvain Dorel, Frank Bignet, Jeanick Brisswalter, et al.. INFLUENCE OF GENDER ON PACING ADOPTED BY ELITE TRIATHLETES DURING A COMPETITION. European Journal of Applied Physiology, 2009, 106 (4), pp.535-545. 10.1007/s00421009-1043-4 . hal-01713184

\section{HAL Id: hal-01713184 https://hal-insep.archives-ouvertes.fr/hal-01713184}

Submitted on 20 Feb 2018

HAL is a multi-disciplinary open access archive for the deposit and dissemination of scientific research documents, whether they are published or not. The documents may come from teaching and research institutions in France or abroad, or from public or private research centers.
L'archive ouverte pluridisciplinaire $\mathbf{H A L}$, est destinée au dépôt et à la diffusion de documents scientifiques de niveau recherche, publiés ou non, émanant des établissements d'enseignement et de recherche français ou étrangers, des laboratoires publics ou privés. 
Paru dans :

European journal of applied physiology (ISSN 1439-6327), 2009, vol. 106, no4, pp. 535-545

Editorial Manager(tm) for European Journal of Applied Physiology Manuscript Draft

Manuscript Number: EJAP-D-09-00049R1

Title: INFLUENCE OF GENDER ON PACING ADOPTED BY ELITE TRIATHLETES DURING A COMPETITION

Article Type: Original Articles

Keywords: triathlon; performance; race design; power output

Corresponding Author: Dr. Christophe Hausswirth, PhD

Corresponding Author's Institution: National Institute of Sport and Physical Education (INSEP)

First Author: Yann Le Meur, PhD

Order of Authors: Yann Le Meur, PhD; Christophe Hausswirth, PhD; Sylvain Dorel, PhD; Frank Bignet; Jeanick Brisswalter, Professor; Thierry Bernard, PhD

Abstract: Purpose: The aim of this study was to compare the pacing strategies adopted by women and men during a World Cup ITU triathlon. Methods: Twelve elite triathletes ( 6 females, 6 males) competed in a World Cup Olympic distance competition where speed and heart rate (HR) were measured in the three events. The power output (PO) was recorded in cycling to determine the time spent in 5 intensity zones ([0-10\% VT1 [ ; $10 \%$ VT1-VT1 [ ; [VT1-VT2 [ ; [VT2-MAP[ and $\geq$ MAP) (VT : ventilatory threshold; MAP : maximal aerobic power). Results: Swimming and running speeds decreased similarly for both genders $(\mathrm{p}<0.05)$ and HR values were similar through the whole race $(92 \pm 2 \%$ and $92 \pm 3 \%$ of maximal HR for women and men, respectively). The distribution of time spent in the 5 zones during the cycling leg was the same for both genders. The men's speed and PO decreased after the first bike lap ( $<<0.05)$ and the women spent relatively more time above MAP in the hilly sections ( $45 \pm 4 \%$ vs. $32 \pm 4 \%)$. The men's running speed decreased significantly over the whole circuit, whereas the women slowed only over the uphill and downhill sections ( $\mathrm{p}<0.05)$. Conclusion: This study indicates that both female and male elite triathletes adopted similar positive pacing strategies during swimming and running legs. Men pushed the pace harder during the swim-to-cycle transition contrary to the women and female triathletes were more affected by changes in slope during the cycling and running phases.

Response to Reviewers: See attachment 


\title{
INFLUENCE OF GENDER ON PACING ADOPTED BY ELITE TRIATHLETES DURING A COMPETITION
}

\author{
YANN LE MEUR ${ }^{1,2}$, CHRISTOPHE HAUSSWIRTH ${ }^{1}$, SYLVAIN DOREL $^{1}$, \\ FRANK BIGNET $^{3}$, JEANICK BRISSWALTER $^{2} \&$ THIERRY BERNARD $^{2}$ \\ 1 "Research Department", Laboratory of Biomechanics and Physiology, National Institute of \\ Sport and Physical Education (INSEP), 75012 Paris, FRANCE. \\ ${ }^{2}$ University of South Toulon-Var, HANDIBIO EA 3162, 83957 La Garde Cedex, FRANCE. \\ ${ }^{3}$ French Federation of Triathlon, Saint-Denis-La-Plaine, FRANCE
}

\section{Corresponding Author:}

Dr Christophe Hausswirth, PhD, Assistant Professor

« Research Department », National Institute of Sport and Physical Education (INSEP),

11 Avenue du Tremblay, 75012 Paris, FRANCE

Phone : 33 1-41-74-43-85

Fax : + 33 1-41-74-45-35

E-mail : christophe.hausswirth@insep.fr 


\section{$\underline{\text { Responses to reviewer } 1}$}

Each critical point has been taken into consideration either straightly by changes in the text using red characters or discussed in the present file.

- We agree that it would be useful to show representative samples of the data to give a sense of the temporal resolution that the mean values are based on for the three phases, like Stapelfelt et al. study (Int J Sports Med, 2004, 25(4): 294-300) about pacing strategies in mountain bike racing. Nevertheless, we already included 4 graphs and 4 tables in the present manuscript and the reviewer 2 encouraged us to reduce this amount. We think that the 4 present graphs are essential to compare pacing strategies for women and men. In this context, even if we would have preferred to include this fifth graph, we feared that the latter wouldn't be accepted by the other reviewers. In addition, it would be difficult to represent on the same graph the evolution of speed during the three disciplines and SRM data for one woman and one man (meaning 2 more graphs).

- As reported in paragraph 38 line 17 , the distribution of the time spent into the 5 intensity zones is comparable to the data collected for both genders during cycling events lasting 3 to 4 hours (Ebert et al., 2005 and Vogt et al. (2006) for women and men, respectively). In accordance with your observation, we have strengthened this comparison: "Ebert et al. (2005) demonstrated that female elite cyclists spent 52\% (zone 1 + zone 2), 22\% (zone 3), 13\% (zone 4) and 13\% (zone 5) of 3-hour hilly world cup cycling races into the intensity zones assessed previously during laboratory testing. Similarly, the present data are comparable with a study of Vogt et al. (2006) concerning a 6-stage race of 215-minute mean time performed by male professional cyclists. The distribution of time in the different intensities was $58 \%$ for zone $1,14 \%$ for zone 2 and $28 \%$ at intensities higher than an increase in $1 \mathrm{mM}$ above the lactate threshold (zone 3). Thus, the variability of the power output during a world cup event triathlon seems to be comparable to professional cycling events, even if the duration of the cycling leg was shorter in the present study (i.e. $66 \mathrm{~min} 31 \mathrm{sec} \pm 1 \mathrm{~min} 07$ and 59 $\min 12 \pm 3 \min 09$, for women and men, respectively) than in the studies previously mentioned.

\section{$\underline{\text { Responses to reviewer } 2}$}

Methods

- The method to determine swimming positions have been precised in the text. Paragraph 14 : "Position was determined at $350 \mathrm{~m}, 750 \mathrm{~m}$ and $1500 \mathrm{~m}$ for each triathlete of the race ( $n=157 ; 70$ women, 87 men) during the swim thanks to their personal race number written on their swim cap and using the video system previously described for a further analysis."

Results

- Paragraph 24: the correction has been directly added in the text. "A significant inverse correlation was observed between the percentage of time spent above MAP in the hills and the MAP/weight ratio $(\mathrm{r}=-0.73, p<0.05 ; \mathrm{n}=12) . "$ 
- We have included the MAP/weight ratio for both male and female in the Table 1.

- In accordance with your comment, we have decided to discuss about the difference in cycling cadence between women and men. The main points are the following:

o This study is the first to compare the effect of gender on freely chosen cycling cadence during a competition.

○ Only Vandewalle et al. (Eur J Appl Physiol Occup Physiol, 1987, 56(6): 650-6) have described higher cycling cadence for men during force-velocity tests performed on cycle ergometer compared with women (difference ranging from $4.7 \%$ to $8.0 \%$ according to the population studied). According to these authors the lower values of maximal cadence observed in women could be partly explained by a crank length that was not adjusted to the small size of the subjects. If we don't exclude this explanation, SRM crank length were adjusted to the leg length of each triathlete in the present study (crank lengths were $170.8 \mathrm{~cm}$ and $173.8 \mathrm{~cm}$, for women and men, respectively).

- Marsh and Martin (1997) showed that less-trained cyclists may select lower pedaling cadence to reduce aerobic demand. In the present study, we observed indeed that women had weaker maximal aerobic capacity than men $(60.9 \pm 7.0$ $\mathrm{mlO}_{2} \cdot \mathrm{min}^{-1} \cdot \mathrm{kg}^{-1}$ vs. $\left.71.7 \pm 5.4 \mathrm{mlO}_{2} \cdot \mathrm{min}^{-1} \cdot \mathrm{kg}^{-1}, p<0.01\right)$ and that their mean cycling training volume was smaller than men $(215 \pm 32 \mathrm{~km}$ per week vs. 298 $\pm 45 \mathrm{~km}$ per week, for women and men, $p<0.01)$.

- We observed that women spent relatively more time over the hilly sections compared with men $(20.8 \pm 1.5 \%$ of total cycling time vs. $15.3 \pm 4.9 \%$ of total cycling time, for women and men, respectively, $p<0.05$ ). As lower cadences were spontaneously adopted over the hills, we think that the weaker MAP/weight ratio of women can also explain why they adopted lower mean cycling cadence.

O In this context, a new paragraph has been added regarding the effect of gender on cycling cadence: "Men adopted a higher mean cycling cadence than women (95 \pm 4 rpm vs. $88 \pm 4 \mathrm{rpm}$, respectively, $p<0.05$ ). To the best of our knowledge, this study is the first to compare the effect of gender on freelychosen cycling cadence during an international competition. Only Vandewalle et al. (1987) previously described higher cycling cadence for men during forcevelocity tests performed on cycle ergometer compared with women (difference ranging from $4.7 \%$ to $8.0 \%$ according to the population studied). We speculate that this effect of gender could be partly due to difference in cycling skills and maximal aerobic capacity. Indeed, Marsh and Martin (1997) showed that less-trained cyclists may select lower pedaling cadence to reduce aerobic demand. In the present study, we observed that women had weaker maximal aerobic capacity than men $\left(60.9 \pm 7.0 \mathrm{mlO}_{2} \cdot \mathrm{min}^{-1} \cdot \mathrm{kg}^{-1}\right.$ vs. $71.7 \pm 5.4 \mathrm{mlO}_{2} \cdot \mathrm{min}^{-}$ $\left.{ }^{1} \cdot \mathrm{kg}^{-1}, p<0.01\right)$ and that their mean cycling training volume was smaller than men $(215 \pm 32 \mathrm{~km}$ per week vs. $298 \pm 45 \mathrm{~km}$ per week, $p<0.01)$. In addition, we observed that women spent relatively more time over the hilly sections compared with men $(20.8 \pm 1.5 \%$ of total cycling time vs. $15.3 \pm 4.9 \%$ of total cycling time, for women and men, respectively, $p<0.05)$. As lower 
cadences were spontaneously adopted over the hills, we think that the weaker MAP/weight ratio of women can also explain why they adopted lower mean cycling cadence compared to men."

- Results of table 3 (power output) have been added to figure 2 (cycling speed) and results of table 4 (mean running speed) have been added to figure 4 .

Discussion

- We agree that the relation between cycling cadence and muscular fatigue is controversial (e.g. Lepers et al. Med Sci Sport Exerc 2001, Sarre \& Lepers Acta Physiol Scand 2005). In this context, we deleted "It is well documented that selecting a high cadence with a lower gear reduces the force per pedal stroke, and muscular fatigue (Takaishi et al 2002)" (paragraph 37).

- Page 16 line 14 : The reference has been modified. Hausswirth C, Brisswalter J (2008) Strategies for improving performance in long duration events: Olympic distance triathlon. Sports Med 38:881-91 has been changed by Hausswirth C, Bernard T, Vallier JM, Vercruyssen F, Brisswalter J (2004) Effect of different running strategies on running performance in Olympic distance triathlon. Proceedings of the 7th annual congress of the ECSS; 2002 Jul 24-28; Athens: 183

Specific

- Page 10 line 5 : the correction has been directly added in the text.

- Page 11 line 13 : the correction has been directly added in the text.

- Page 9, line 17: the correction has been directly added in the text.

\section{$\underline{\text { Responses to reviewer } 3}$}

- Maximum has been replaced by maximal throughout the text.

- Page 3 line 10: the correction has been directly added in the text.

- Page 7 line 5: the correction has been directly added in the text.

- Page 8 line 19: the correction has been directly added in the text.

- Page 14 line 1: the correction has been directly added in the text.

- Page 16 line 3: the correction has been directly added in the text.

- Page 16 line 20: the correction has been directly added in the text.

- Page 16 Line 21: the correction has been directly added in the text.

- Page 17 Line 4: the correction has been directly added in the text.

- Page 17 Line 5: "massive running start" has been changed by "the running start in pack"

- Page 17 line 16: the correction has been directly added in the text.

- Page 17 Line 17: the correction has been directly added in the text.

- Page 17 Line 24: the correction has been directly added in the text. 
- Page 20 line 8: the correction has been directly added in the text. 


\section{Abstract}

2 Purpose: The aim of this study was to compare the pacing strategies adopted by women and 3 men during a World Cup ITU triathlon. Methods: Twelve elite triathletes (6 females, 6

4 males) competed in a World Cup Olympic distance competition where speed and heart rate

5 (HR) were measured in the three events. The power output (PO) was recorded in cycling to 6 determine the time spent in 5 intensity zones ([0-10\% VT1[ ; [10\% VT1-VT1[ ; [VT1-VT2[ ; 7 [VT2-MAP[ and $\geq$ MAP) (VT : ventilatory threshold; MAP : maximal aerobic power).

8 Results: Swimming and running speeds decreased similarly for both genders $(p<0.05)$ and 9 HR values were similar through the whole race $(92 \pm 2 \%$ and $92 \pm 3 \%$ of maximal HR for women and men, respectively). The distribution of time spent in the 5 zones during the cycling leg was the same for both genders. The men's speed and PO decreased after the first bike lap $(p<0.05)$ and the women spent relatively more time above MAP in the hilly sections (45 $\pm 4 \%$ vs. $32 \pm 4 \%$ ). The men's running speed decreased significantly over the whole circuit, whereas the women slowed only over the uphill and downhill sections $(p<0.05)$.

Conclusion: This study indicates that both female and male elite triathletes adopted similar positive pacing strategies during swimming and running legs. Men pushed the pace harder during the swim-to-cycle transition contrary to the women and female triathletes were more affected by changes in slope during the cycling and running phases.

\section{Keywords: triathlon, performance, race design, power output}


1

\section{INTRODUCTION}

8

Paragraph 1 In an attempt to enhance our understanding of athletic performance, sports scientists have examined how workload or energy expenditure is distributed during an exercise task (Foster et al. 2004, Tucker et al. 2006). This distribution of workload, or variability in energy expenditure, has been termed "pacing" or "pacing strategy" (Atkinson 6 and Edwards 1998, Foster et al. 2004). In a review on pacing strategy and athletic 7 performance, Foster et al (Foster et al. 1994) recall that, since the initial study by Robinson et al. (1958) during a $1.2 \mathrm{~km}$ run, there have been few systematic studies to determine how various pacing strategies might influence the outcome of competition performance. These research studies have mainly focused on cycling and running (for review, see Abbiss and Laursen 2008). Nevertheless, all these studies described the variability in energy expenditure in one gender, generally males. The way the conclusion could be extended to the other gender still remains unclear. To the best of our knowledge, only three studies focusing on swimming, rowing and triathlon investigated whether gender differences exist in pacing (Thompson et al. 2000, Garland et al., 2005, Vleck et al. 2008). Vleck et al. (2008) have notably demonstrated that during a short distance triathlon under "draft-legal" conditions (i.e. $1.5 \mathrm{~km}$ swim, $40 \mathrm{~km}$ cycle and $10 \mathrm{~km}$ run), women adopted the same strategies as men over swimming and running sections but did not tend to "bridge gaps" during the bike phase. This particular strategy of female triathletes increased the impact of cycling on their overall performance. Differentiating pacing between women and men could be useful to better design training programs according to the demands of competition.

Paragraph 2 During the last decade, studies focusing on factors affecting performance during a short distance triathlon have identified the role of drafting position (Hausswirth et al. 1999, Hausswirth et al. 2001), power output production (Bernard et al. 2007), cycling cadence selection (Vercruyssen et al. 2005, Vleck et al. 2006) or previous locomotion mode on subsequent exercise (Hausswirth et al. 1996, Hausswirth et al. 1997) as the main factors 
1 explaining changes in performance during triathlon. Nevertheless, these studies were not

2 carried out under competition conditions and did not consider gender effects on the responses 3 observed. Recently, Vleck et al. (2006) were the first to describe the pacing strategies $4 \quad$ spontaneously adopted by elite triathletes during a World Cup Event. They demonstrated that

5 the top $50 \%$ of triathletes in the race differ from those who place in the bottom $50 \%$ of the 6 field in so far as they swim significantly faster in the early stages of the event. This tactic 7 involved greater work in the initial stages of the cycle stage for the weaker swimmers and 8 might influence subsequent running performance. For all that the authors did not discuss the 9 way these findings could be generalised to women. In this context, the study by Vleck et al. (2006) remains the only one that has differentiated pacing strategies between female and male elite triathletes using a field-based analysis. Nevertheless, this study was limited in its ability to describe the variability in workload demands during an International Triathlon Union World Cup (ITU WC) race because of its lack of details concerning "performance power" (via heart rate and power output data).

Paragraph 3 One year before the Olympic Games in Beijing 2008, we were allowed to collect data during a World Cup event, which took place on the same circuit as the Olympic race. The aim of this study was to describe the pacing strategies adopted by female and male elite triathletes during a World Cup triathlon and to discuss possible factors influencing the self-selection of such strategies. The Beijing ITU WC triathlon China 2007 was an opportunity to characterise the effects of gender on the swimming, cycling and running workloads during an elite short distance triathlon.

\section{MATERIAL AND METHODS}

Subjects

Paragraph 4 Twelve triathletes (6 women, 6 men) from the French and Swiss national triathlon teams participated in this study. They were familiar with all testing procedures and 
1

gave their informed written consent to take part to this study that was conducted according to

2 the Declaration of Helsinki. A local committee (Saint Germain en Laye, France) for the

3 protection of individuals gave approval concerning the project before its initiation. Mean ( \pm

$4 \quad \mathrm{SD})$ characteristics of the subjects are presented in Table 1.

5

$6 \quad$ Pre-race maximal testing

7

8

Paragraph 5 Two weeks before the competition, each subject performed a maximal test in swimming, cycling and running in a randomized order. These tests were separated by a 48-hour rest period.

Paragraph 6 Swimming Maximal Test. Triathletes performed an all-out 400-m front crawl test in a 25-m swimming pool in order to determine their swimming maximal heart rate $\left(\mathrm{HR}_{\max }\right)$ (Lavoie and Montpetit, 1986). Heart rate (HR) values were monitored using a Polar unit at a sampling rate of $0.2 \mathrm{~Hz}$ (Team System, Polar Electro Kempele, Finland).

Paragraph 7 Cycling Maximal Test. Each subject performed an incremental cycling test until volitional exhaustion, to estimate maximal oxygen uptake $\left(\dot{\mathrm{V}} \mathrm{O}_{2 \max }\right)$, maximal aerobic power (MAP) and ventilatory thresholds. This laboratory session was conducted on a stationary electromagnetically braked cycle ergometer (SRM ergometer, Schoberer Rad Messtechnik, Jülich, Germany). The system is a crank-based device that measures the mechanical power output using strain gauges attached to components inside the crank. The measured torque and cadence values were digitalized inside the crank, and converted into a high-frequency, pulse-width modulated electrical signal. The data were transmitted to a microcomputer on the handlebar where the torque was averaged over each complete pedal revolution and multiplied by the cadence to calculate the power output reading using the following equation:

Power output $=([$ measured frequency - zero offset frequency $] \mathrm{x}$ cadence $\mathrm{x} 2 \pi) /($ slope $\mathrm{x} 60)$. 
2 the SRM factory. Seat height and crank length were adjusted to the measures used by the 3 athletes on their own racing bikes. After a 6-min warm-up at $100 \mathrm{~W}$, further increments of 25

4 and $30 \mathrm{~W}$ were added every 2 minutes until volitional exhaustion for women and men,

5 respectively. Oxygen uptake $\left(\dot{\mathrm{V}}_{2}\right)$ expiratory flow, $\left(\dot{\mathrm{V}}_{\mathrm{E}}\right)$ were collected and respiratory 6 exchange ratio (RER) was calculated, using a telemetric system (Cosmed $\mathrm{K} 4 \mathrm{~b}^{2}$, Rome, Italy). 7 Heart rate values were monitored using a Polar unit (RS800sd, Polar Electro Kempele, 8 Finland). Expired gases and HR values were averaged every 10 seconds from the breath-by9 breath raw values. $\dot{\mathrm{V}} \mathrm{O}_{2 \max }$ and MAP were defined as the average of the highest consecutive $10 \dot{\mathrm{V}} \mathrm{O}_{2}$ and power output values recorded during a 30 -second period. $\dot{\mathrm{V}} \mathrm{O}_{2 \max }$ was determined 11 according to criteria described by Howley et al (1995) - that is, a plateau in $\dot{\mathrm{V}} \mathrm{O}_{2}$ despite an increase in power output, a respiratory exchange ratio value of 1.15 , or a HR over $90 \%$ of the predicted maximal HR. Moreover, the first and the second ventilatory thresholds (VT1 and VT2, respectively) were determined according to criteria previously described by Beaver et al (1986). The physiological characteristics of the subjects are presented in Table 1.

Paragraph 9 Maximal Running Test. The subjects completed an incremental continuous maximal test on a 400-m track to determinate their maximal running heart rate. The test began at $12 \mathrm{~km} \mathrm{~h}^{-1}$ and the speed was increased by $1 \mathrm{~km} \mathrm{~h}^{-1}$ every 3 minutes until volitional exhaustion. The test was considered maximal when the criteria previously described by Howley et al (1995) were reached. HR values were monitored using a Polar unit at a sampling rate of $0.2 \mathrm{~Hz}$ (Team System, Polar Electro Kempele, Finland).

\section{Triathlon race field testing}

Paragraph 10 Race data were collected during the Beijing ITU World Cup (China, September 15th and 16th, 2007). The circuit of the competition was exactly the same as that 
1 of the Olympic event in 2008 in Beijing

12 (http://www.triathlon.org/images/event/maps/beijingcoursemap.pdf). The swimming phase of

3 the test-event consisted of a single $1500 \mathrm{~m}$. Wetsuits were not allowed due to the temperature

4 of the water $\left(23^{\circ} \mathrm{C}\right)$. The cycle phase consisted of six laps of $6.5-\mathrm{km}$ laps $(39.2 \mathrm{~km})$, which

5 included a hill (difference in altitude of $100 \mathrm{~m}$ per lap after $1.4 \mathrm{~km}$ with a $820 \mathrm{~m}$ hill at a $6 \%$

6 gradient). The running leg consisted of an out and back lap, comprising three times of $2.4 \mathrm{~km}$

7 hilly-laps plus a final lap of $2.90 \mathrm{~km}(10.1 \mathrm{~km}$, a change in altitude of $60 \mathrm{~m}$ per lap condensed 8 in a $300 \mathrm{~m}$ hill at a $12 \%$ gradient).

9

\section{Speed measurements.}

Paragraph 11 Swimming phase. A video analysis system at $25 \mathrm{~Hz}$ (Sony HDR-CX12 AVHD) was synchronized with the official timing system (Omega, Swatch Group, Swiss). Three digital cameras were situated at the swim start, at $350 \mathrm{~m}$, at $750 \mathrm{~m}$ and at the swim exit $(1507 \mathrm{~m})$. The distances between these points were measured using a global positioning system, whose accuracy performance was of 2-3 meters (GPS, Garmin GPSRAP 60CSx, Garmin Europe, UK). Thus, swimming speed $\left(\mathrm{m} . \mathrm{s}^{-1}\right)$ was recalculated via a subsequent video analysis (3D vision ${ }^{\circledR}$, Biometrics, Orsay, France).

Paragraph 12 Cycling phase. Before the event, each subject's own bicycle was equipped with a mobile power measurement device (Gardner et al 2004). Cycling speed (km $\mathrm{h}^{-1}$ ) was calculated for each lap with a SRM system (Professional SRM road version, SRM Training System, Schoberer Rad Messtechnik, Jülich, Germany). The system weight of $300 \mathrm{~g}$ is comparable to a conventional bicycle crank, and thereby does not influence performance. Because of a possible drift of the zero offset frequency, the device was systematically calibrated prior to the race. Data were collected at a sampling-rate of $1 \mathrm{~Hz}$.

Paragraph 13 Running phase. Running velocity was continuously recorded using a s3 accelerometer (Polar RS800sd, Kempele, Finland). This is a very small commercial device 
1 (3.5 $\mathrm{x} 0.7 \mathrm{~cm})$, light in weight $(20 \mathrm{~g})$ with a time-sampling mechanism that allows it to

2 provide chronological measures of running speed. Its accuracy and reliability have recently

3 been validated (in press). Three days before the race, the s3 sensor was calibrated, as

4 recommended by the manufacturer, to integrate each runner's stride characteristics. Subjects

5 had to follow a pace close to the speed they adopt in competition (i.e. $16 \mathrm{~km} \mathrm{~h}^{-1}$ and $20 \mathrm{~km} \cdot \mathrm{h}^{-1}$

6 for women and men, respectively) throughout one kilometer. This speed was paced by a

7 cyclist on a bike equipped with the SRM system previously described. Run data were

8 subsequently pooled for flat, uphill and downhill sections (whose lengths were $1760 \mathrm{~m}, 300 \mathrm{~m}$

9 and $300 \mathrm{~m}$, respectively for lap1-3 and $2290 \mathrm{~m}, 300 \mathrm{~m}, 300 \mathrm{~m}$ for lap4). These data were

Paragraph 14 Ranking associated with isolated and overall performances. Position was determined at $350 \mathrm{~m}, 750 \mathrm{~m}$ and $1500 \mathrm{~m}$ for each triathlete of the race $(n=157 ; 70$ women, 87 men) during the swim thanks to their personal race number written on their swim cap and using the video system previously described for a further analysis. For both cycling and running, isolated position linked with the performance achieved in each event (i.e. isolated swimming, cycling or running position) was recalculated using the official timing system. It provided split-times for swim-to-cycle and cycle-to-run transitions, cycling and running phases. To ensure the accuracy of these isolated rankings, we recalculated them using cameras located at the beginning and at the end of cycling and running sections. Triathletes who did not finish the race were not included during further analyses $(n=30 ; 11$ women and 19 men). Thus, a total of 127 triathletes were taken into account.

Paragraph 15 Power output and cadence recording. The SRM system records power output, cadence and distance continuously and reliably. These values were collected at a sampling rate of $1 \mathrm{~Hz}$. 
Paragraph 16 To analyze the time spent at different power outputs during

2 competition, the amounts of competition time (in percentage of cycling time) was distributed

3 in 5 intensity zones: below $10 \%$ of maximal aerobic power, above $10 \%$ of maximal aerobic

4 power and below power output at first ventilatory threshold, above $\mathrm{P}_{\mathrm{VT} 1}$ and below power

5 output at second ventilatory threshold, above $\mathrm{P}_{\mathrm{VT} 2}$ and below $100 \%$ of maximal aerobic power 6 (<100\% MAP) and above $100 \%$ of maximal aerobic power $(>100 \%$ MAP).

7

Paragraph 17 Heart Rate recording. Subjects were equipped with a Polar unit (Team system, Kempele, Finland) to record HR throughout the swim, cycle and run phases of the triathlon. These data were recorded at a sampling rate of $0.2 \mathrm{~Hz}$. After the race, they were transmitted from the registration unit to a personal computer for further processing. For further analyses, all data were expressed as a percentage of the $\mathrm{HR}_{\max }$ values reached during laboratory testing.

\section{Statistical analysis}

Paragraph 18 Descriptive statistics [mean, standard deviation (SD)] for speed and \% $\mathrm{HR}_{\max }$ were calculated for swimming, cycling and running legs. The same method was employed for power output and cadence during the cycle phase. Those data were pooled considering the sections previously described. The effect of gender and change in altitude were analyzed using a two way repeated measures ANOVA (gender $\mathrm{x}$ time) using power output, speed, cadence and HR as dependent variables. A Tukey post-hoc test was used to determine any differences between both populations or between the sections. Pearson's product moment correlation was used to determine the relationship between overall race position and isolated positions associated with the performance achieved during swimming, cycling and running phases. The same method was used to determine the relationship between the percentage of time spent above MAP in the hilly section of the cycling phase and the MAP/weight ratio. For all analyses, the level of significance was accepted at $p<0.05$. 
1

\section{RESULTS}

\section{Overall performance and position}

3

4

Paragraph 19 The mean finish times of the triathletes studied were 125 min $43 \pm 2$ min 07 and $111 \min 05 \pm 1$ min 08 for women and men, respectively $(p<0.01)$. The mean

final rankings were $26 \pm 16$ and $30 \pm 16$ for women and men, respectively $(p>0.05)$

Compared to the whole population of the race (i.e. 75 women and 85 men), women finished in the top $35.7 \pm 18.0 \%$ and men in the top $35.1 \pm 20.8 \%(p=0.96)$

\section{Swimming phase}

Paragraph 20 A significant difference was observed between women and men for swimming speed and time $\left(1.24 \pm 0.03 \mathrm{~m} \mathrm{~s}^{-1} v s .1 .38 \pm 0.05 \mathrm{~m} \mathrm{~s}^{-1}\right.$ and $20 \min 09 \mathrm{sec} \pm 24 \mathrm{sec}$ vs. $18 \mathrm{~min} 07 \mathrm{sec} \pm 40 \mathrm{sec}$, respectively, $p<0.01)$. Speeds over the first $350 \mathrm{~m}$ of the swim were faster than any other swim sections $(p<0.05)$. In addition, the position after $350 \mathrm{~m}$ strongly determined the position reached at the end of the swim both for females and males, when considering all competitors $(r=0.97$ and $r=0.99, p<0.01$, respectively). A weak correlation between the rank after the swimming section and the final position were observed for the whole population $(r=0.47$ and $r=0.36, p<0.01$, for women and men, respectively; Table 2).

Paragraph 21 No significant effect of gender was observed on HR values (92 \pm 2 and $91 \pm 3 \% \mathrm{HR}_{\max }, p>0.05$, for women and men, respectively; Fig. 1).

\section{Cycling phase}

Paragraph 22 The 12 triathletes on whom we focused on, completed the cycle phase of the triathlon in $66 \mathrm{~min} 31 \mathrm{sec} \pm 1 \mathrm{~min} 07 \mathrm{sec}$ and in $59 \min 12 \mathrm{sec} \pm 3 \mathrm{~min} 09 \mathrm{sec}$, at $35.4 \pm$ $0.6 \mathrm{~km} \mathrm{~h}^{-1}$ and $39.6 \pm 0.1 \mathrm{~km} \mathrm{~h}^{-1}$ for women and men, respectively $(p<0.01)$. Women's mean power output was $181 \pm 22 \mathrm{~W}\left(3.16 \pm 0.39 \mathrm{~W} \mathrm{~kg}^{-1}\right)$ and men's was $265 \pm 27 \mathrm{~W}(3.96 \pm 0.22$ 
$\left.1 \mathrm{~W} \mathrm{~kg}^{-1}\right)(p<0.01)$. The speed $\left(\mathrm{km} \mathrm{h}^{-1}\right)$ and mean power output at each point of the cycle stage are presented in Fig. 2.

Paragraph 23 No significant difference was observed between females and males 4 concerning the $\%$ of MAP sustained during the bike section. Mean relative intensities were $5 \quad 61.4 \pm 7.5 \%$ MAP and $63.4 \pm 6.5 \%$ MAP for women and men, respectively $(p>0.05)$. No 6 effect due to gender was observed when those data were expressed in time spent in the 5 7 zones of intensity determined from the laboratory incremental test (Fig. 3). The average 8 distribution of time spent at different intensities in presented in Fig. 3.

Paragraph 24 A significant effect of gender appeared concerning the geographic distribution of time spent above MAP. Indeed, whereas women spent $44.8 \pm 4.1 \%$ of total cycling time above MAP during hills, males only spent $31.9 \pm 4.4 \%(p<0.05)$. A significant inverse correlation was observed between the percentage of time spent above MAP in the hills and the MAP/weight ratio $(\mathrm{r}=-0.73, p<0.05, \mathrm{n}=12)$. This ratio was significantly better for men $(p<0.05)$.

Paragraph 25 Regarding pedaling cadence, significant lower mean values were observed in women $(88 \pm 4 \mathrm{rpm})$ compared to men $(95 \pm 4 \mathrm{rpm}, p<0.05)$. No significant time effect was observed in either gender $(p>0.05)$. On the contrary, we recorded a significant decrease in distance per pedaling cycle for both genders $(-3.1 \%$ and $-2.0 \%, p<0.05$ between lap1 and lap6 for women and men, respectively).

Paragraph 26 Besides, a significant correlation was observed between the final position and the isolated cycling position for both women and men $(\mathrm{r}=0.68$ and $\mathrm{r}=0.52, p<$ 0.01, respectively; Table 2). Moreover, a significant correlation between isolated swimming position and isolated cycling position both was observed for women $(\mathrm{r}=0.35, p<0.01)$ but not for men $(\mathrm{r}=-0.22, p>0.05)$. 
Paragraph 27 No significant difference between women and men were observed on

HR values $\left(91 \pm 3\right.$ and $90 \pm 3 \% \mathrm{HR}_{\max }, p>0.05$, for women and men; Fig. 1). On the

3 contrary, HR values significantly decreased for both genders $(p<0.05)$.

4

5

\section{Running phase}

Paragraph 28 A significant difference between women and men for mean running speed and time $\left(15.6 \pm 0.5 \mathrm{~km} \mathrm{~h}^{-1}\right.$ vs. $18.4 \pm 0.5 \mathrm{~km} \mathrm{~h}^{-1}$ and $38 \min 35 \mathrm{sec} \pm 1 \min 09 \mathrm{sec} v s$. $33 \min \pm 1 \min 09 \mathrm{sec}, p<0.01)$ and during each lap was observed $(p<0.01)$. The speed $(\mathrm{km}$ $\left.\mathrm{h}^{-1}\right)$ at each point of the running leg is presented in Fig. 4.

Paragraph 29 During the running phase during flat, downhill and uphill sections for men, the speed decreased significantly $(p<0.05$; Fig. $4 \mathrm{~b})$.

Paragraph 30 Finally, a positive correlation between the final position and the isolated running ranking was found both for women and men $(\mathrm{r}=0.77, p<0.05$ and $\mathrm{r}=0.98$, $p<0.01$ for women and men, respectively; Table 2). The isolated running ranking was not correlated with swimming and bike isolated position both for women and men $(p>0.05)$.

Paragraph 31 No significant effect of time and gender was observed on HR values (93 \pm 2 and $94 \pm 2 \% \mathrm{HR}_{\max }, p>0.05$, for women and men; Fig. 1).

\section{DISCUSSION}

Paragraph 32 The purpose of this study was to compare the pacing strategies adopted by women and men during a World Cup ITU triathlon. In this context, the distribution of workload in the three events have been quantified for both genders. This study illustrated how gender affects overall performance, evolution of speed, power in cycling and metabolic responses associated with performance during an elite short distance triathlon. The main findings of this study were: (1) that both female and male elite triathletes adopted similar pacing strategies by starting fast before decreasing their pace whatever the different phases; 
1 (2) the decrease in pace during the cycling phase was more pronounced in men than in

women; (3) during both cycling and running phases, women were more affected than men by changes in slope; (4) no effect of gender was observed on the relative intensities reached during the overall phases.

\section{Similarities between elite female and male triathletes}

Paragraph 33 The first similarity of the population studied concerned the race 8 ranking/whole triathletes ratio. Then, the global level of the relative performance of the 9 triathletes studied was quite similar for both women and men and all data collected were 10 therefore comparable.

Paragraph 34 The present swim data revealed that both women and men adopted a similar "positive pacing strategy", whereby after peak swimming speed was reached, triathletes progressively slowed (Abbiss and Laursen 2008). The velocity was significantly higher for both genders between the start pontoon and the first timing point localised at $350 \mathrm{~m}$ than during the last $1150 \mathrm{~m}$ of the swimming phase $(p<0.01)$. The performance of triathletes during the initial part of the swimming phase appeared to be decisive for the ranking observed at the exit of water for women and men $(r=0.97$ and $r=0.99$, respectively; $p<0.01)$. These results extended to previous observations about elite female triathletes (Vleck et al. 2008), which showed that the first 400 to $500 \mathrm{~m}$ of the swim stage appeared to be critical for the development of the swimming section as a whole during a men's ITU WC race. Though, research findings published on pacing strategies showed that "positive pacing" might be detrimental for performance during events lasting more than 3 minutes (Abbiss and Laursen 2008, Foster et al. 1994). By reaching the first places of the pack, triathletes avoided congestion at the first turn-around buoy where weaker swimmers in the rear part of the group were disadvantaged. Thus, even if female and male triathletes swim $1500 \mathrm{~m}$ during ITU WC triathlons, they would take advantage to improve their ability to swim fast on shorter distances. As demonstrated by Thompson et al. (2003), adopting a positive pacing elicits a 
1 high anaerobic demand, a capacity to increase the fast component of $\dot{\mathrm{V}} \mathrm{O}_{2}$ and an ability to 2 reach higher stroke rates.

3

4

Paragraph 35 HR values revealed also a similarity between both genders, as female and male triathletes performed at $92 \pm 2 \% \mathrm{HR}_{\max }$ and $91 \pm 3 \% \mathrm{HR}_{\max }$, respectively $(p>0.05$; Fig. 1). It confirmed the highly intense character of elite short distance triathlon races (i.e. Olympic distance), already described for recreational triathletes by Delextrat et al. (2003). To reduce this metabolic workload, both genders should principally optimize their sheltered position to reduce passive drag (Chatard and Wilson 2003). According to Chatard and Wilson (2003), elite triathletes should strategically adopt a position inside the peloton instead of on the side of it.

Paragraph 36 This study revealed the minor impact of swimming performance on overall race position both for women and men (Table 2). A weak but significant correlation was found between the positions at the water exit and at the arrival for both genders $(r=0.47$ and $r=0.36, p<0.05$, for women and men, respectively; Table 2). These findings confirmed previous results (Vleck et al. 2008) which reported similar correlations during the 2002 Lausanne ITU WC $(r=0.47$ and $r=0.39, p<0.01$, for women and men, respectively). Vleck et al. (2006) hypothesized that the weaker swimmers, who constituted the cycling chasing packs, have to ride harder over the first $20-\mathrm{km}$ to "catch up with" the leading triathletes, which led to weaker overall performance. In this perspective, the more the swimming phase creates cycling packs, the more its own ranking would influence the final ranking.

Paragraph 37 The similarity between women and men elite triathletes pacing strategy during the cycling phase only concerned the global positive split strategy adopted during this section (Fig. 2). Both genders decreased significantly cycling speeds between the initial part and the final part of the cycling phase $(-5.6 \%$ and $-4.6 \%$ between lap1 and lap6, $p<0.05$, for women and men, respectively). The power output decreased significantly during the same period by $19.4 \%$ and $16.8 \%$, for women and men, respectively $(p<0.05)$. Similarly to Vleck 
1 et al. study (2008) focusing on the Lausanne 2002 ITU WC, we hypothesised that this could

2 be explained by the fact that the number of packs was stabilized before the cycle-to-run 3 transition, contrary to the post-swim phase (i.e. no change in packs composition was observed 4 for both genders after lap-3). Thus, athletes' organization within the pack allowed them to 5 strongly reduce the workload delivered associated with a slight decrease in cycling speed. The 6 first experimental studies using constant cycling power output exercise have suggested that 7 performance could be improved when athletes are able to run as fast as possible immediately 8 after the cycling leg (Hausswirth et al. 2001). During a variable cycling protocol, Suriano et 9 al. (2007) have observed that decreasing power during the last five minutes of the ride leads to (1) an increase in running performance. Furthermore, when athletes try to increase power output at the end of the cycling part to come into the transition area in the best position, a significant decrease in running time was observed (Bernard et al. 2007). During the race, no cadence variation was observed for either gender with a mean value $(88 \pm 4 \mathrm{rpm}$ and $95 \pm 4 \mathrm{rpm}$ for women and men, respectively) higher than those previously reported in professional road cyclists during flat and hilly rides (75 $\pm 4 \mathrm{rpm}$ and $75 \pm 4 \mathrm{rpm}$, respectively) in females (Ebert et al. 2005) and ( $87 \pm 14 \mathrm{rpm}$ and $81 \pm 15 \mathrm{rpm}$, respectively) in males (Vogt et al. 2007). In this context, the steady-state of pedaling cadence was related to a progressive decrease in distance per pedaling cycle $(-3.1 \%$ and $-2.0 \%, p<0.05$ between lap1 and lap6 for women and men, respectively) and power output $(-19.4 \%$ and $-16.8 \%, p<0.05$; Table 2) within laps. This indicates that the reduction in power was primarily due to a reduction in force or torque and that the athletes simply chose appropriate gearing to maintain their preferred cadence whatever the gender. In addition HR values decreased for both gender between the first and the second half part of the cycling phase $(-3.0 \%$ and $-6.0 \% p<0.05$, for women and men, respectively; Fig. 1); this result suggests that this strategy reduced also the metabolic workload. Therefore, we could suggest that in this competition context of Olympic distance 
1 triathlon both female and male choose a strategy to reduce fatigue at the end of the cycling

part in order to maximise the subsequent running performance.

4

Paragraph 38 A strong likeness between women and men in the global distribution of the time spent in the 5 zones of intensity was observed. This resemblance suggested that women don't try more than men to save energy during the cycle leg for the subsequent run. This finding questions the results of Vleck et al. (2008) who suggested that females did not particularly tend to "bridge gaps" in the cycling section during the Lausanne 2002 ITU WC. The authors described a decrease in cycling speeds for all female bike packs. In contrast males at the rear packs tended to push the pace in order to "catch up to" the leading athletes. According to these authors (Vleck et al. 2008), anecdotal evidence (personal communications) suggested that this pacing is characteristic of elite females but they could not know whether it is deliberate or reflects fatigue. In addition, we observed no significant difference between women and men for the time spent in zone 1 (above 10\% MAP). This result reveals that both genders tended to optimize similarly the periods of time when they could coast down in freewheel within the peloton. The global distribution of the time spent in the 5 zones of intensity was also comparable with previous studies focusing on professional cycling competitions of 3-4 hour duration for both genders. Ebert et al. (2005) demonstrated that female elite cyclists spent 52\% (zone $1+$ zone 2), $22 \%$ (zone 3), $13 \%$ (zone 4) and 13\% (zone 5) of 3-hour hilly world cup cycling races into the intensity zones assessed previously during laboratory testing. Similarly, the present data are comparable with a study of Vogt et al. (2006) concerning a 6-stage race of 215-minute mean time performed by male professional cyclists. The distribution of time in the different intensities was $58 \%$ for zone $1,14 \%$ for zone 2 and $28 \%$ at intensities higher than an increase in $1 \mathrm{mM}$ above the lactate threshold (zone 3 ). Thus, the variability of the power output during a world cup event triathlon seems to be comparable to professional cycling events, even if the duration of the cycling leg was shorter in the present study (i.e. $66 \min 31 \mathrm{sec} \pm 1 \min 07$ and $59 \min 12 \pm 3 \min 09$, for women and 
1

men, respectively) than in the studies previously mentioned. This similarity was confirmed by

2 HR values, as female and male triathletes performed at $91 \pm 3 \% \mathrm{HR}_{\max }$ and $90 \pm 3 \% \mathrm{HR}_{\max }$,

3 respectively $(p>0.05$; Fig. 1$)$. Strategically, in order to reduce the high metabolic workload,

4 triathletes would have to take benefit in drafting during cycling by maintaining a continuous

5 sheltered position (Hausswirth et al. 2001).

6

7 8 precisely the first $1500 \mathrm{~m}$ ) was run significantly faster for all triathletes of both genders.

9 Nevertheless, no concomitant decrease in HR values for both women and men throughout the

Paragraph 39 Concerning the running phase, the pacing strategy adopted was the same, regardless of gender (Fig. 4). With no exception $(n=127)$, the first lap (and more running leg was observed ( $p>0.05$; Fig. 1), whereas running speed decreased significantly for both genders during the same period ( $p<0.05$; Fig. 4). These opposite evolutions revealed a decrease of running efficiency for both genders. The benefit of this positive pacing strategy (i.e. positive split) systematically adopted by elite triathletes still remains unclear (Hausswirth and Brisswalter 2008; Vleck et al. 2006; Vleck et al. 2008). It appears to be highly questionable to push the pace at the start of the post-cycling phase when blood flow is still not well redistributed according to running particular demands (Hausswirth and Brisswalter 2008, Kreider et al. 1988). Hausswirth and Brisswalter (2008) demonstrated that in well-trained triathletes the best running strategy following cycling was to perform the first kilometer 5\% slower than the average speed of an isolated 10-km run (212.9 s vs. $202.8 \mathrm{~s}$, respectively) to achieve the best performance (2000 s vs. 2028 s). The increase in running speed over the first kilometer was linked significantly to a poorer performance in the 10-km run (2178 s). As each triathlete of the present study adopted the same positive strategy (i.e. their speed decreases throughout the running phase), pacing might be the main factor to improve running performance in ITU WC events whatever the gender, and is not yet optimised by triathletes.

Paragraph 40 Running performances were significantly correlated with the overall finishing position for both female and male triathletes $(r=0.77$ and $0.98, p<0.01$, 
1
10

respectively; Table 2). This result is even more relevant for men whose mean running speeds nearly determined their finishing position. Similarly, Vleck et al. (2008) have reported that the running speed was highly correlated with overall race results during the Lausanne 2002 ITU WC ( $\mathrm{r}=-0.71, p<0.001$ and $\mathrm{r}=-0.94, p<0.01$ for women and men, respectively). This

5 gender effect seemed to be due to the running start in pack observed during the race by the

6 men in the present study. As swimming and cycling phases did not discriminate between male

7 triathletes, their final ranking was determined by their running performance. For women, even

8 if running speed determined strongly their final ranking, the latter mostly influenced the final 9 ranking within each cycling pack.

\section{Differences between elite female and male triathletes}

Paragraph 41 Contrary to swimming and running phases, cycling results revealed that women and men adopted different pacing strategies during the initial part of the cycling phase. Men pushed the pace (i.e. cycling speed) over the first lap before decreasing it over the subsequent laps $(p<0.05$; Fig. 2). On the contrary, women had no significant variation in cycling speed until the last lap which was ridden more slowly $(p<0.05)$. These results were confirmed by mechanical workload values with a decreased of $16.8 \%$ in power output for men between lap1 to lap3 $(p<0.05)$, whereas no significant decrease was recorded during the same period for women ( $p=0.60$; Fig. 2).

Paragraph 42 The distribution of time in the different intensities during the two first laps (results not presented) revealed that men spent significantly more time than women in zone $3(+7 \%, p<0.05)$ and less time in zone $2(-8 \%, p<0.05)$. No significant effect of gender was found for the distribution of time spent in zones 1,4 and $5(p>0.05)$. Therefore, men cycled at a higher relative intensity than women over the initial part of the cycling section by reducing the time of light intensity.

Paragraph 43 An effect of gender on cycle workload concerning the distribution of high power output bursts (zone 5; refer to cycling phase results part) was observed. Although 
1 no effect of gender on the relative time spent in zone 5 was noticed (> MAP; Fig. 3), a

2 significant effect of circuit design on the distribution of power output above MAP was

3 observed. Men reached zone 5 during technical bike sections (i.e. changes in direction) to stay

4 in their pack, while women spent more time above their MAP in the hilly sections. The

5 present results confirmed the previous report (Vleck et al. 2008) that noticed that the critical

6 point at which the fragmentation of the bike field occurred was over a $10-15 \%$ gradient hill

7 during the female Lausanne 2002 ITU WC. The significant reverse correlation between the

8 relative time spent above MAP in hills and the MAP/weight ratio $(\mathrm{r}=-0.73, p<0.05)$

9 corroborates the previous suggestion. Given the significant difference between females and males about this ratio $(p<0.05)$, this conclusion has clear training implications. Women should focus more on their aptitude for "climbing" in improving their cycling skills or their MAP/weight ratio (Davison et al. 2000). Men would take advantage to improve their aptitude for accelerating in bettering their Maximal Anaerobic Power / weight ratio and their ability to reproduce short sprints with incomplete recovery. Then, athletes could reduce the specific fatigue effects generated by hills and changes in direction or, on the contrary, push the pace in those sections. Nevertheless, these conclusions remain limited to hilly circuits presenting technical sections like the present one and previous Olympic circuits (i.e. 2000 Sydney and 2004 Athens Olympic races).

Paragraph 44 Men adopted a higher mean cycling cadence than women during the race $(95 \pm 4 \mathrm{rpm} v s .88 \pm 4 \mathrm{rpm}$, respectively, $p<0.05)$. To the best of our knowledge, this study is the first to compare the effect of gender on the freely-chosen cycling cadence during an international competition. Only Vandewalle et al. (1987) previously described higher cycling cadence for men during force-velocity tests performed on cycle ergometer compared with women (difference ranging from $4.7 \%$ to $8.0 \%$ according to the population studied).. We speculate that this effect of gender could be partly due to difference in cycling skills and maximal aerobic capacity. Indeed, Marsh and Martin (1997) showed that less-trained cyclists 
1

may select lower pedalling cadence to reduce aerobic demand. In the present study, we observed that women had weaker maximal aerobic capacity than men $\left(60.9 \pm 7.0 \mathrm{mlO}_{2} \cdot \mathrm{min}^{-}\right.$ ${ }^{1} \cdot \mathrm{kg}^{-1}$ vs. $\left.71.7 \pm 5.4 \mathrm{mlO}_{2} \cdot \mathrm{min}^{-1} \cdot \mathrm{kg}^{-1}, p<0.01\right)$ and that their mean cycling training volume

4 was smaller than men $(215 \pm 32 \mathrm{~km}$ per week vs. $298 \pm 45 \mathrm{~km}$ per week, for women and men,

5 respectively, $p<0.01)$. In addition, we observed that women spent relatively more time over 6 the hilly sections compared with men $(20.8 \pm 1.5 \%$ of total cycling time $v s .15 .3 \pm 4.9 \%$ of

7 total cycling time, for women and men, respectively, $p<0.05)$. As lower cadences were 8 spontaneously adopted over the hills, we think that the weaker MAP/weight ratio of women 9 can also explain why they adopted lower mean cycling cadence compared to men.

Paragraph 45 The present findings revealed a greater prevalence of isolated cycling performance on overall ranking for women $(\mathrm{r}=0.68$ and $\mathrm{r}=0.52, p<0.01$ for women and men, respectively; Table 2). In our view, the gender effect was mainly due to the number of cycle packs, which ended the bike leg. Whereas the 50 first triathletes of both genders were grouped into three packs at swim exit, only male packs number 2 and 3 managed to join quickly the first bike pack. On the one hand, men's cycling results were very homogeneous and a massive pack reached the running start at the same time (55 of the 67 finishers). In addition, as packs 2 and 3 joined the leading pack only after 2 laps during the male race, no residual effects of pushing the pace over the initial part of the cycling phase seemed to be prevalent during the running phase. On the other hand, a 2 min $20 \mathrm{sec}$ gap spaced the 27 first women from the chasing groups (including 30 women). Thus, women's final rankings were strongly determined by cycling speed, as the advance gained by the leading group was high enough to prevent the return of the following triathletes. These findings are in accordance with Vleck et al. (2008) who supposed that the smaller field size and the lower field density of women favor the preservation of the packs during the cycling phase of ITU WC races. Therefore, elite females with better swimming and cycling abilities than the rest of the field may incur a relatively greater competitive edge at the run start than elite males. 
2 different slopes on the decrease in running speed (Fig. 4). Women decreased their speed

3 throughout the run only over decline and incline sections, whereas men did the same in all

4 parts of the circuit. Moreover, all triathletes tended to have less and less benefit of the

5 downhill sections during the running leg (-12\% grade, Fig 4). Except for the first lap, the

6 speed downhill was not significantly different from the speed adopted over the flat sections

7 for both women and men. Like cross country runners, both female and male triathletes'

8 training should include changes in topography to improve their ability for adjusting their

9 stride rate and length despite fatigue.

10

Paragraph 47 In conclusion, the present study demonstrated that elite female and male triathletes adopted similar positive pacing strategies during swimming, cycling and running phases. However, men pushed the pace on the bike during the post-swim phase and reached high power output bursts (>MAP) over "technical bike sections". The decrease in speed was less pronounced during the cycling phase and they seemed to suffer more from changes in slope during both cycling and running sections. Further investigations are needed to determine whether these conclusions were influenced by race dynamics and if they can be extended to other race conditions (i.e. circuit design, start list size and density, meteorological conditions). 


\section{Acknowlegments}

12 This study was supported by technical supports to the French National Institute of Sport and 2

33 Physical Education, the French Federation of Triathlon and the University of South Toulon- 
$\frac{1}{2}$
3

4

5

\section{REFERENCES}

Abbiss CR, Laursen PB (2008) Describing and understanding pacing strategies during athletic competition. Sports Med 38:239-52

Atkinson G, Edwards B (1998) Pacing strategy and cycling performance: field data from the 1997 British $16 \mathrm{~km}$ time-trial championship [abstract]. In: Sargeant AJ, Siddons H, editors. Proceedings of the Third Annual Congress of the European College of Sports Science. Liverpool: centre for Health Care Development, p211

Beaver WL, Wasserman K, Whipp BJ (1986) A new method for detecting anaerobic threshold by gas exchange. J Appl Physiol 60:2020-7

Bernard T, Vercruyssen F, Mazure C, Gorce P, Hausswirth C, Brisswalter J (2007) Constant versus variable-intensity during cycling: effects on subsequent running performance. Eur J Appl Physiol 99:103-11

Chatard JC, Wilson B (2003) Drafting distance in swimming. Med Sci Sports Exerc $35: 1176-81$

Davison RC, Swain D, Coleman D, Bird S (2000) Correlates of simulated hill climb cycling performance. J Sports Sci 18:105-10

Delextrat A, Tricot V, Bernard T, Vercruyssen F, Hausswirth C, Brisswalter J (2003) Drafting during swimming improves efficiency during subsequent cycling. Med Sci Sports Exerc 35:1612-9

Ebert TR, Martin DT, McDonald W, Victor J, Plummer J, Withers RT (2005) Power output during women's World Cup road cycle racing. Eur J Appl Physiol 95:529-36

Foster C, Schrager M, Snyder AC, Thompson NN(1994) Pacing strategy and athletic performance. Sports Med 17:77-85

Foster C, deKoning JJ, Hettinga F, Lampen J, Dodge C, Bobbert M, Porcari JP (2004) Effect of competitive distance on energy expenditure during simulated competition. Int $\mathbf{J}$ Sports Med 25:198-204 
Gardner AS, Stephens S, Martin DT, Lawton E, Lee H, Jenkins D (2004) Accuracy of SRM and power tap power monitoring systems for bicycling. Med Sci Sports Exerc 36:125258

Garland SW (2005) An analysis of the pacing strategy adopted by elite competitors in 2000

$5 \quad$ m rowing. Br J Sports Med 39:39-42

6 Hausswirth C, Bigard AX, Berthelot M, Thomaïdis M, Guezennec CY (1996) Variability 7 in energy cost of running at the end of a triathlon and a marathon. Int J Sports Med 17:572-9

8 Hausswirth C, Bigard AX, Guezennec CY (1997) Relationships between running 9 mechanics and energy cost of running at the end of a triathlon and a marathon. Int J Sports

Med 18:330-9

Hausswirth C, Lehénaff D, Dréano P, Savonen K (1999) Effects of cycling alone or in a sheltered position on subsequent running performance during a triathlon. Med Sci Sports Exerc 31:599-604

Hausswirth C, Vallier JM, Lehenaff D, Brisswalter J, Smith D, Millet G, Dreano P (2001) Effect of two drafting modalities in cycling on running performance. Med Sci Sports Exerc $33: 485-92$

Hausswirth C, Bernard T, Vallier JM, Vercruyssen F, Brisswalter J (2004) Effect of different running strategies on running performance in Olympic distance triathlon. Proceedings of the 7th annual congress of the ECSS; 2002 Jul 24-28; Athens: 183

Hausswirth C, Le Meur Y, Couturier A, Bernard T, Brisswalter J (in press) Accuracy and repeatability of the Polar ${ }^{\circledR}$ RS800sd to evaluate stride rate and running speed. Int J Sports Med

Howley ET, Bassett DR Jr, Welch HG (1995) Criteria for maximal oxygen uptake: review and commentary. Med Sci Sports Exerc 27:1291-301

Kreider RB, Boone T, Thompson WR, Burkes S, Cortes CW (1988) Cardiovascular and thermal responses of triathlon performance. Med Sci Sports Exerc 20:385-90 
Lavoie JM, Montpetit RR (1986) Applied physiology in swimming. Sports Med 3:165-89

2 Marsh AP, Martin PE (1997) Effect of cycling experience, aerobic power, and power output on preferred and most economical cycling cadences. Med Sci Sports Exerc 29:1225-32

4 Robinson S, Robinson DL, Mountjoy RJ, Bullard RW (1958) Influence of fatigue on the

5 efficiency of men during exhausting runs. J Appl Physiol 12:197-201

6 Suriano R, Vercruyssen F, Bishop D, Brisswalter J (2007) Variable power output during 7 cycling improves subsequent treadmill run time to exhaustion. J Sci Med Sport 10:244-51

8 Thompson KG, Haljand R, MacLaren DP (2000) An analysis of selected kinematic 9 variables in national and elite male and female 100-m and 200-m. J Sports Sci 18:421-31 swimming. Eur J Appl Physiol 88:438-43

Tucker R, Marle T, Lambert EV, Noakes TD (2006) The rate of heat storage mediates the anticipatory reduction in exercise workrate during cycling in the heat at a fixed perceived exertion. J Physiol 574:905-15

Vandewalle H, Peres G, Heller J, Panel J, Monod H (1987) Force-velocity relationship and maximal power on a cycle ergometer. Correlation with the height of a vertical jump. Eur $\mathbf{J}$ Appl Physiol Occup Physiol 56:650-6

Vercruyssen F, Suriano R, Bishop D, Hausswirth C, Brisswalter J (2005) Cadence selection affects metabolic responses during cycling and subsequent running time to fatigue.

Br J Sports Med 39:267-72

Vleck VE, Bürgi A, Bentley DJ (2006) The consequences of swim, cycle, and run performance on overall result in elite olympic distance triathlon. Int J Sports Med 27:43-8

Vleck VE, Bentley DJ, Millet GP, Bürgi A (2008) Pacing during an elite Olympic distance triathlon: Comparison between male and female competitors. J Sci Med Sport 11:424-32

Vogt S, Heinrich L, Schumacher YO, Blum A, Roecker K, Dickhuth HH, Schmid A 
1 (2006) Power output during stage racing in professional road cycling. Med Sci Sports Exerc $2 \quad 38: 147-51$

3 Vogt S, Schumacher YO, Roecker K, Dickhuth HH, Schoberer U, Schmid A, Heinrich L 4 (2007) Power Output during the Tour de France. Int J Sports Med 28:756-61

5 
FIGURE 1. Evolution of mean $( \pm \mathrm{SD}) \mathrm{HR}\left(\% \mathrm{HR}_{\max }\right)$ throughout the race for women and men.

Swim1 : 0-350m; Swim2 : 350-750m; Swim3 : 750-1500m; Bike1 : 0-20km;Bike2: 20-40km; Run1 : 0-2.4km; Run2: 2.4-4.8km; Run3 : 4.8-7.2km; Run4: 7.2-10.1km.

No significant differences were observed between female and male triathletes $(p<0.05)$.

FIGURE 2. Cycling speed (average $\pm \mathrm{SD}, \mathrm{km} \cdot \mathrm{h}^{-1}$ ) and power output (average $\pm \mathrm{SD}, \mathrm{W}$ ) over each bike lap for females $(n=6)$, males $(n=6)$.

* Significantly different from the previous lap $(p<0.05)$.

$\$$ Significantly different from LAP1 $(p<0.05)$.

FIGURE 3. Distribution of exercise time spent in intensity zones: below $10 \%$ of maximal aerobic power (zone 1), above $10 \%$ of maximal aerobic power and below power output at first ventilatory threshold $\left(<\mathrm{P}_{\mathrm{VT} 1}=64.9 \pm 3.9 \% \mathrm{MAP}\right.$; zone 2$)$, above $\mathrm{P}_{\mathrm{VT} 1}$ and below power output at second ventilatory threshold $\left(<\mathrm{P}_{\mathrm{VT} 2}=82.3 \pm 3.3 \%\right.$ MAP; zone 3$)$, above $\mathrm{P}_{\mathrm{VT} 2}$ and below $100 \%$ of maximal aerobic power $(<100 \%$ MAP; zone 4$)$ and above $100 \%$ of maximal aerobic power (> 100\% MAP; zone 5).

No significant differences were observed $(p<0.05)$.

FIGURE 4. Mean $( \pm \mathrm{SD})$ running speed $\left(\mathrm{km} \cdot \mathrm{h}^{-1}\right)$ during the triathlon for women $(n=6$; a) and men $(n=6 ; b)$ on flat, downhill, uphill sections and the all circuit.

* Significantly different from the previous lap $(p<0.05)$.

$\$$ Significantly different from LAP1 $(p<0.05)$.

$£$ Significantly different from flat speed $(p<0.05)$. 


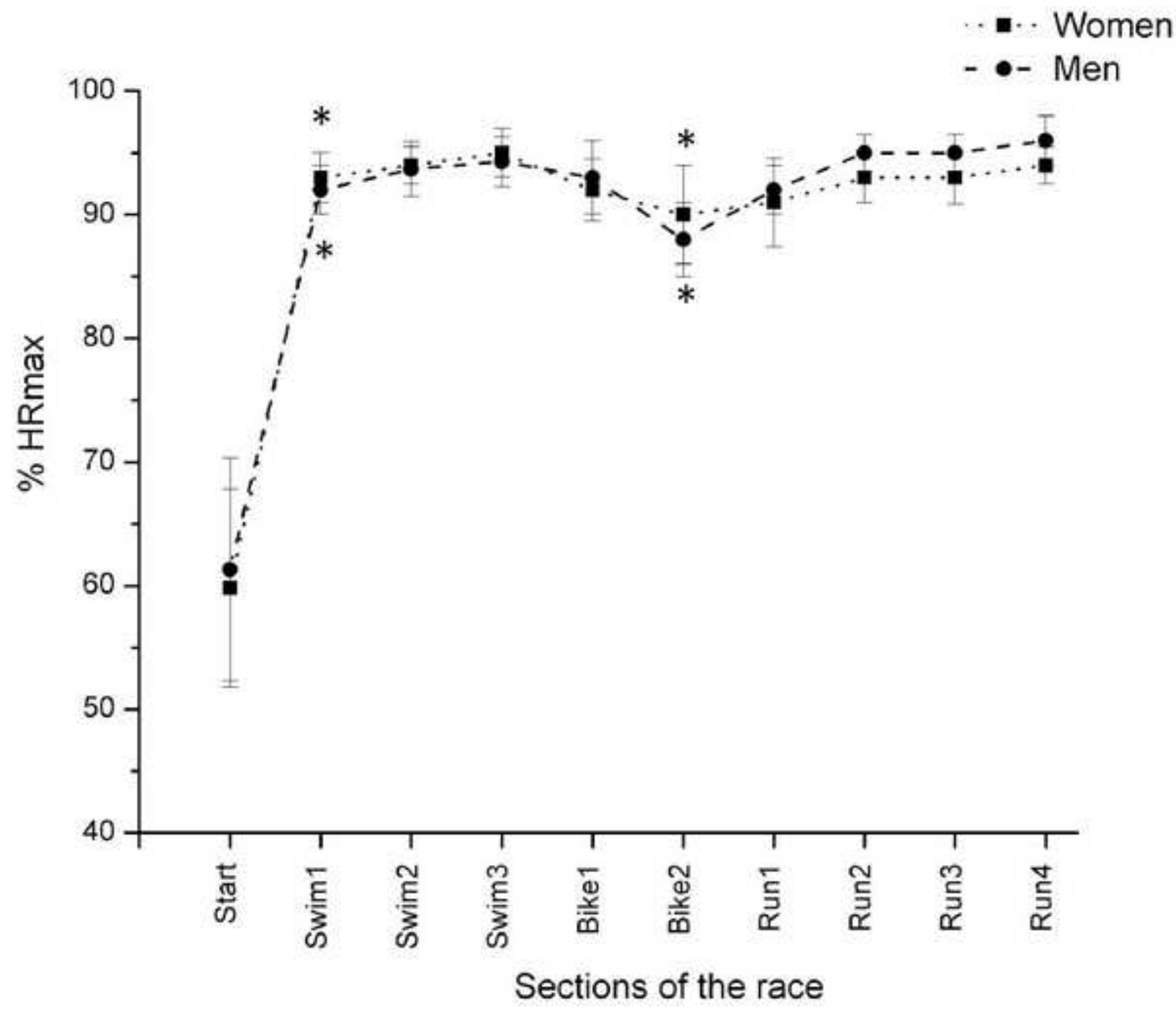




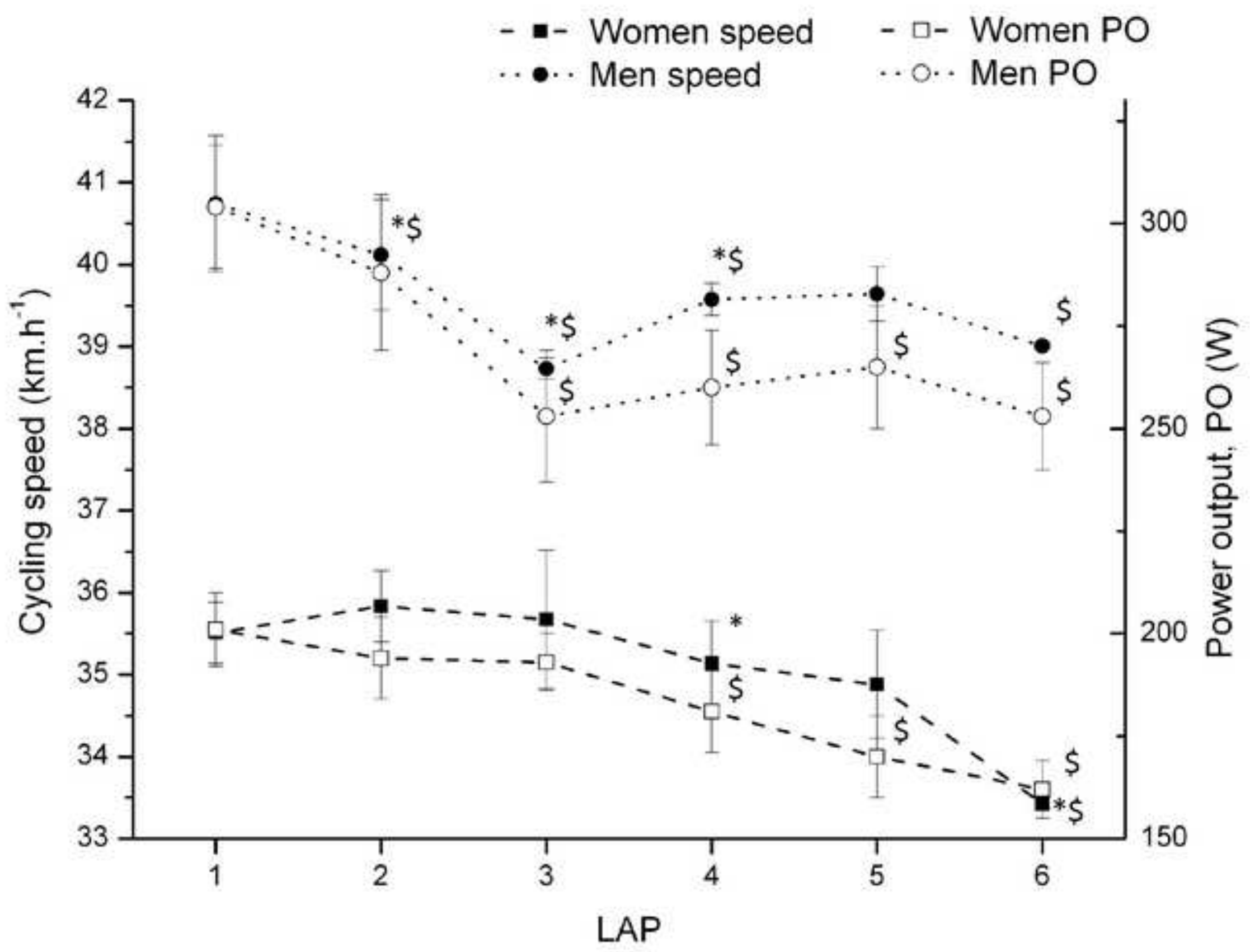




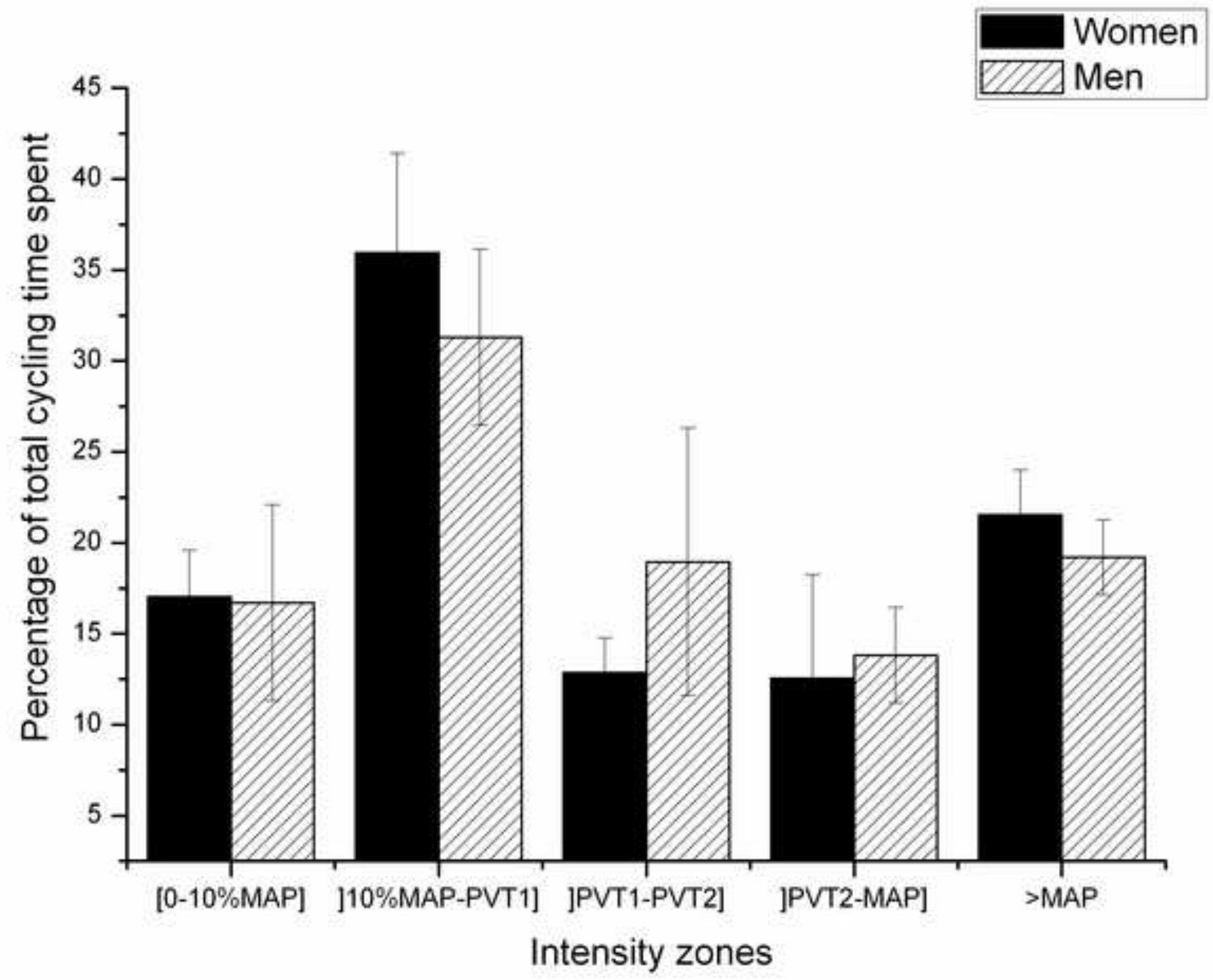


Figure4

Click here to download high resolution image

a.

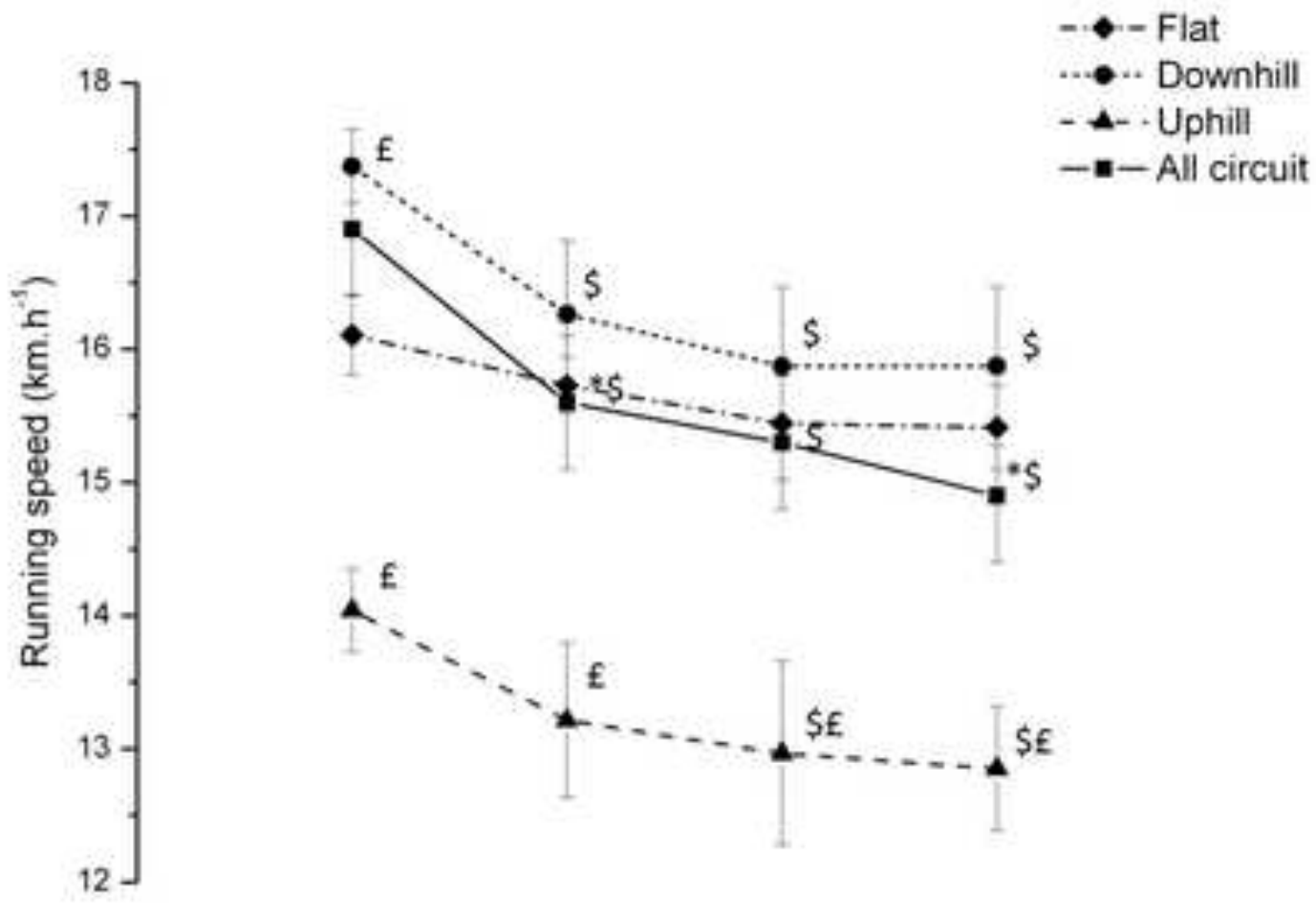

b.

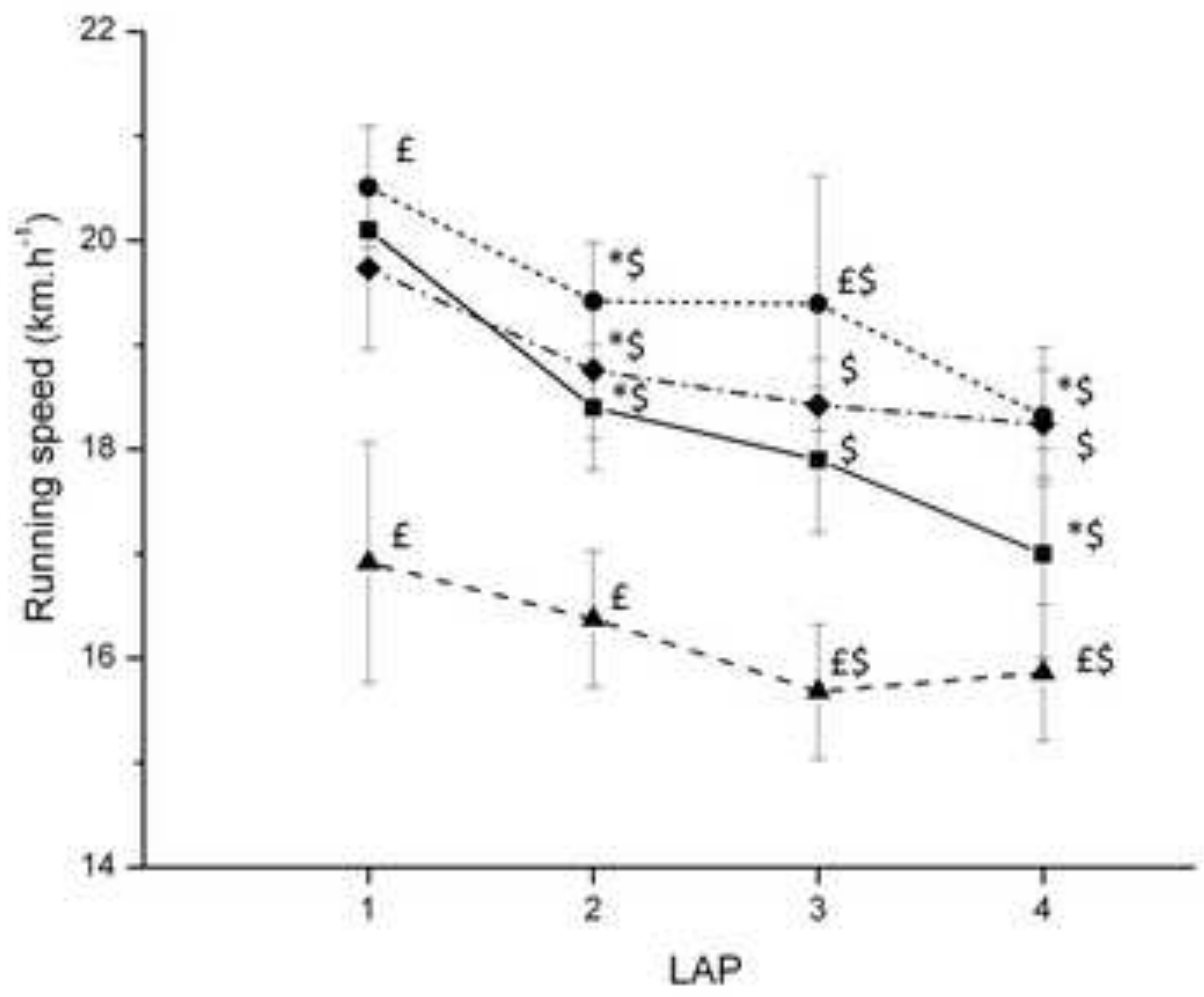


TABLE 1. Anthropometrical and physiological characteristics of the triathletes (Females, $n=6$; Males, $n=6$ ).

\begin{tabular}{lll}
\hline Parameters & Women & Men \\
\hline Age (years) & $27 \pm 4$ & $30 \pm 6$ \\
Weight $(\mathrm{kg})$ & $57 \pm 5$ & $67 \pm 5$ \\
Height $(\mathrm{cm})$ & $168 \pm 5$ & $180 \pm 3$ \\
$\dot{\mathrm{V}} \mathrm{O}_{2} \mathrm{max}\left(\mathrm{mlO}_{2} \cdot \mathrm{min}^{-1} \cdot \mathrm{kg}^{-1}\right)$ & $60.9 \pm 7.0$ & $71.7 \pm 5.4$ \\
$\mathrm{MAP}(\mathrm{W})$ & $293 \pm 19$ & $418 \pm 22$ \\
$\mathrm{MAP} / \mathrm{weight}\left(\mathrm{W} \cdot \mathrm{kg}^{-1}\right)$ & $5.2 \pm 0.2$ & $6.2 \pm 0.2$ \\
$\mathrm{P}_{\mathrm{VT} 1}(\mathrm{~W})$ & $201 \pm 21$ & $264 \pm 20$ \\
$\mathrm{P}_{\mathrm{VT} 1}(\% \mathrm{MAP})$ & $68.6 \pm 7.1$ & $63.2 \pm 4.8$ \\
$\mathrm{P}_{\mathrm{VT} 2}(\mathrm{~W})$ & $232 \pm 24$ & $349 \pm 22$ \\
$\mathrm{P}_{\mathrm{VT} 2}(\% \mathrm{MAP})$ & $79.2 \pm 8.2$ & $83.5 \pm 5.3$ \\
\hline
\end{tabular}

$\dot{\mathrm{V}} \mathrm{O}_{2}$ max: maximal oxygen uptake, MAP: Maximal aerobic power, $\mathrm{P}_{\mathrm{VT} 1}$ : Power output at the first ventilatory threshold, $\mathrm{P}_{\mathrm{VT2}}$ : Power output at the second ventilatory threshold. 
TABLE 2. Correlation matrix between the ranking for each event considered individually and the final race position for overall triathletes of the race $(n=59$ and $n=$ 68 for women and men, respectively).

\begin{tabular}{llll}
\hline Gender & $\mathbf{r}_{\text {Swim }}$ & $\mathbf{r}_{\text {Bike }}$ & $\mathbf{r}_{\text {Run }}$ \\
\hline Female & $0.47^{*}$ & $0.68^{*}$ & $0.77^{*}$ \\
Male & $0.36^{*}$ & $0.52^{*}$ & $0.98^{*}$ \\
\hline
\end{tabular}

$* p<0.01$. 